\title{
Erratum to: Sustainable Fashion
}

\author{
Sarah Margaretha Jastram and Anna-Maria Schneider
}

\section{Erratum to:}

\section{S. M. Jastram, A.-M. Schneider (eds.), Sustainable Fashion, Management for Professionals, https://doi.org/10.1007/978-3-319-74367-7}

This book was inadvertently published with the incorrect editor sequence as Anna-Maria Schneider and Sarah Margaretha Jastram. The editor sequence has been corrected throughout the book except chapter 1 as Sarah Margaretha Jastram and Anna-Maria Schneider. 